IJMS 17 (Special Issue), 35-50 (2010)

\title{
MONEY IMPARTIALITY: PANACEA FOR ECONOMIC CRISIS
}

\author{
JAMAL OTHMAN \\ Faculty of Economics and Business \\ Universiti Kebangsaan Malaysia
}

\begin{abstract}
This paper overviews the political-economics of FIAT and asset-based money. The paper further highlights the presumably syaria standpoint of the impartial character of money as the fundamental factor that differentiates asset-based money from the FIAT money. It is argued that while it is ideal for asset-based money to make a comeback in the interest of holistic wellbeing (maslahah) of humankind, it is necessary to complement it with an appropriate financial and regulatory system to safeguard its impartiality, i.e. non-tradable, non-interest bearing, and non-debt financing to avoid the recurring pitfalls which are immanent in the conventional financial system. It is hoped this rather concise paper will offer a thought provoking discourse on how syaria principles may present the world a useful ideological construct for a new monetary and financial architecture in light of the global financial crisis.
\end{abstract}

Keywords: Asset-based money; FIAT money; Syaria perspectives of money; money impartiality; money and sustainable development; money and financial crisis.

\section{Introduction}

There is increasing agreement among scientists, economists, theologians, politicians, policymakers, and social and development analysts alike, that wellbeing sustainability ${ }^{1}$ of humankind which necessitates the balanced consideration of economic-material progress, socio-cultural properties, and the resiliency of ecological systems, shall be the crucial driving cause in every national planning agenda and development pursuit across the globe. This paper espouses an ideological thought on the roles of money and monetary system on the wellbeing sustainability of mankind across cultures and nations. This paper is prompted by two observations; i) the 
recurring international financial crises that results in the disarray of economic progress and human resource development, and ii) high economic-material growth over the past four decades accompanied by inflationary pressures and degradation of ecological resiliency, environmental quality, and socio-cultural properties that might impair the ability of economies to sustain the level of socio-economic development and wellbeing of mankind in the future. This paper emphasises the adverse repercussions of the non-neutrality attribute of conventional (FIAT) money in economic processes and suggests that any new international financial architecture necessarily requires money to be neutral or impartial to ensure wellbeing sustainability. It will be shown that such neutrality of money is indeed consistent with the viewpoints of money as prescribed by the Islamic syaria. Subsequent sections discuss the essence of FIAT and commodity based money. This is followed by a deliberation on the fundamental factors that differentiate the syaria and contemporary held views of money and its implication. The paper ends with an ideological brief on the way forward for the return of commodity-based money, namely gold and silver or a mix of highly regarded assets or commodities.

\section{The Political Economics of FIAT Money}

FIAT money, as is well known, relates to the type of money that generates value and demand through the legal imposition or assurance by monetary authorities. Hence it is also known as the Government's money. Money made of metals or any commodity is also FIAT money, if it fetches a higher price than the market value of the base (metal or commodity) itself. The concept of Food Stamps as practised in the U.S for her welfare programme is also a kind of FIAT money.

FIAT money has existed in many parts of the world throughout history including the period of Islamic rule. However, never in the history of mankind, the use of FIAT money is more widespread and pervasive now than ever, since the demise of the Breton Woods system in the early 1970s.

\section{Characteristics of FIAT Money}

\section{Devoid of Intrinsic Value}

The most fundamental and unique character of FIAT money is its devoid of intrinsic or organic value. As mentioned earlier, the power of FIAT money is derived from legal tender or put simply the assurance of monetary authorities (central banks) which are legally 
monopolistic. Like the colors of a traffic light, they do not readily generate any meaning upon sight, but we know a red light means a no go because the law says so.

\section{Tradable with Observable "Price Tags"}

This feature is not uniquely attributed to FIAT money but is quite a practice that has been synonymous with the contemporary financial system. The birth of nation states gives rise to the need for countries to introduce own currencies (for national sovereignty) and hence the existence of exchange rates across currencies, albeit a fixed one. Only very few countries are on "dollarisation". When money is deemed a tradable commodity, one may trade, hedge or speculate (either in the spot markets, forward markets, and futures and options market) in any currencies given his/her anticipation of price movements (e.g. interest and inflation rates differentials) or macroeconomic variables (e.g. trade balance) which are thought not to be in tandem with exchange rates movements.

\section{Earn Interest Income}

This character constitutes the life-blood of conventional financial intermediaries across the globe. However, like the second feature, it is not unique to FIAT money alone. In the conventional sense, interest income is seen as a perfectly productive factor rent which stems from the monetisation of utility gain from the use of money capital by economic agents.

\section{The FIAT Money System}

Practically, every country in the world now is using FIAT money. The US dollar remains the world's most important FIAT money, given its dominant role in international trade exchange and official reserves of countries. The world's major commodities and even gold itself are all measured and traded in US dollar. Other currencies notably Euro and Yen still have a lot of catching up before they could manifest into a competitive rival to the dominance of the US dollars. To provide an impression of the extent of 'FIATNESS' of the US dollar, the US does not even possess sufficient gold to pay off a portion of debts of all her foreign investors. As of 30 September 2007, the country had only $\$ 182$ billion in custodial deep storage reserves of gold. This is compared to some $\$ 3$ trillion of total foreign holdings of US treasury bills by the end of 2008. Hence, it is quite possible that at redemption time many of her investors may not be able to regain the value of their principals should the downward drift of the US dollars is sustained. 
FIAT money is associated with the credit monetary system or fractional reserve banking system which creates commercial bank money as multiples of base money devoid of support by the real sector. For instance, in the US, in January 2007, the amount of central bank money was $\$ 750$ billion while the amount of commercial bank money in circulation was $\$ 6.33$ trillion.

It will be extremely hasty or simplistic, perhaps to attribute any economic instability to either FIAT money or asset-based money in entirety. Many early macro-economic crises such as the Great Depression were observed when the US were on gold standard. Surely then the gold standard alone cannot be faulted. One has to examine the entire system in which the gold standard operates. Some studies have indeed attributed the Great Depression to "Bank Runs", where local banks were not able to meet the sudden and massive demand for withdrawals of deposits, ultimately resulting in credit crunch that depressed the economy for a long time. Hence, a return

1) to gold standard or any alternative commodity-based currency as a remedy to the current financial woes will not be sufficient. An appropriate monetary and financial system that upholds and protects the neutrality of money will be necessary. It will be in contrary to common sense economics should gold or any equivalent asset is brought back as currency, but nations or economic agents are allowed to retain their instruments and means to affect exchange rate changes to alter trade competitiveness or to generate profits from currency trading/speculation.

\section{Non-Neutrality of Contemporary Money}

Economic theory presumes that money serves two major functions, viz measure of value, and medium of exchange. This suggests that while money is important to facilitate economic exchanges (production and consumption processes), it is necessarily impartial in the sense that it shall not directly affect the economic structure itself. Like the good gasoline and lubrication oil, it is supposed to keep the engine functioning well and not to affect the engine case in any particular way.

Consider the following system of equations for demand of good $O$;

$$
\begin{aligned}
& P_{O}^{D}=f\left(Q_{O}^{M}, Q_{O}^{S}\right) \\
& Q_{O}^{M}=Q_{O}^{D}+Q_{O}^{E}
\end{aligned}
$$




$$
\begin{aligned}
& Q_{O}^{M}=f\left(P_{O}^{D}, P_{O}^{E}, Y, Y^{*} \bar{S}\right) \\
& \bar{S}=f\left(Q_{O}^{E}, Q_{O}^{I m}, Z\right) \\
& Z=\left(\frac{M}{M^{*}} \varphi\left(\Delta P^{e}-\Delta P^{* e}\right)\left(\frac{Y}{Y^{*}}\right)\right)
\end{aligned}
$$

\begin{tabular}{|c|c|c|}
\hline$P_{O}^{D}$ & $=$ & domestic price of good $O$ \\
\hline$P_{O}^{E}$ & $=$ & export price of good $O$ \\
\hline$Q_{O}^{M}$ & $=$ & market demand for good $O$; \\
\hline$Q_{O}^{S}$ & $=$ & market output supply of good $O$ \\
\hline$Q_{O}^{E}$ & $=$ & export demand for good $O$ \\
\hline Y & $=$ & domestic income; \\
\hline $\bar{S}$ & $=$ & spot exchange rate (e.g. RM per USD); \\
\hline$Z$ & $=$ & $\begin{array}{l}\text { notation representing a host of macroeconomic } \\
\text { variables, namely income, money supply and } \\
\text { inflation rates; }\end{array}$ \\
\hline$Q_{O}^{I m}$ & $=$ & import demand for good $O$; \\
\hline$M$ & $=$ & domestic money supply; \\
\hline$P^{e}$ & $=$ & expected change in domestic inflation rate; \\
\hline$\varphi$ & $=$ & $\begin{array}{l}\text { coefficient for the difference in expected change } \\
\text { in domestic inflation and that of foreign inflation } \\
\text { rates; and }\end{array}$ \\
\hline$\Delta$ & $=$ & changes. \\
\hline
\end{tabular}

Where;

* Asterisk denotes respective variables in the foreign country

The above equations simply illustrate how money, viz changes in exchange rates (Equation 4) eventually (via Equation 3) affects the price determination of marketed goods (Equation 1). Therefore, it is clear that contemporary money fails to be a measure of value as it 
is itself subject to changes via changes in exchange rates, especially in an economy that adopts a non-fixed exchange rate regime. Note also the price or cost of money in a domestic economy is manifested in interest rates, which is yet again a function of money supply and demand, in which case the monopolistic monetary authorities may exert influence through various monetary policy instruments. Contemporary money system and the market mechanism that ensue (such as the various risks management tools) are therefore a logical manifestation of the concept of money that prevails.

The above repercussions are more evident under the present era of globalisation where international capital mobility is close to perfect. Any slight change in the pertinent economic variables (interest rates, inflation, money supply, and exchange rates) whether real time or expected across countries will induce varying anticipatory reactions amongst economic agents.

Marked fluctuations in interest rates (due to the inflationary FIAT money) and exchange rates inevitably lead to the ingenuity of innovative, sophisticated risk management instruments, such as currency futures and options, and currency swaps that even many economists themselves never really fully comprehend. Such instruments may also act as a double-edge sword - either for good hedging or to provide opportunities for profits via speculative indulgence. As is well known, such tools combined with speculative money trading results in perfect capital mobility across the globe that has adverse macroeconomic and wellbeing consequences. The case of the 1997/98 Asian financial crisis is illustrated in Figure 1. The crisis - is an apparent case of international capital departure, comparable to bank runs, leading to various repercussions in the entire economy. A positive and negative sign in the figure denotes an increase and decrease in the said variables, respectively. The figure attempts to illustrate how foreign investors' insight of weaknesses of the Thai export sector led to the short selling of the Thai Baht (The Baht was tied to the US dollar). The Thai National Bank attempted to counter this selling pressure by buying Baht in the open market until they exhausted all their international reserves. This massive plunge of the Baht led to the fear that the currencies of nearby economies would be next targeted, hence the term contagion effect. The ramification of exchange rate changes in the entire economy was very clear. Millions across South-East and East Asia lost their social security overnight without ever understanding what had happened ${ }^{2}$. Even the late President Suharto of Indonesia was reported to be very baffled on 
why Rupiah should plunge in such a drastic manner. As downstream social impacts were amplified, human wellbeing took the final beating. Years of economic-materials achievement gone into the wind. However, in the name of sustainable development and human wellbeing, this writer is not going to show support for high growth policies either.

The apparent reasons for the Asian financial crises have been well documented and understood. Most studies, as anyone would have thought, pointed to policy failures or put plainly, bad macro-economic management. Whatever you point your finger to, to the writer one thing has been very clear. It is the impartiality or double-edge sword effect of money that underlies the brittleness of the conventional financial system. Owing to the pervasive nature of the FIAT money system, understandably but quite despondently this double-edge sword effect is not regarded as morally or legally incorrect. For that matter, when Tun Dr Mahathir, the then Prime Minister of Malaysia was calling those economic agents that gains from currency trading and human adversity as financial robbers/gangsters, it unmistakably falls onto deaf ears.

This author agrees wholeheartedly with Brunnhuber, Fink, and Kuhle (2005) who asserted that six effects, as follows, are inherent in the current financial system. This renders the current financial design incompatible with the notion of sustainable development.

1. Immanent instability of the present financial system.

Currency instability poses uncertainties to all economic agents, consequently sub-optimal decisions are made.

2. Compulsory growth pressure.

Present monetary and financial system exerts systematic pressure to achieve growth at any costs-regardless of whether it makes sense for the entities involved, or enhances the quality of life in a society or not.

3. Short-term orientation.

The present financial system systematically favours short-term projects and discourages investments in long-term ones.

4. Unrelenting concentration of wealth.

Capital owners benefit over-proportionally relative to factor labour. 
5. Towards capital concentration.

Systematic financial incentive towards building huge corporations encouraging a global concentration in many sectors such as energy, car industry, military equipment, and pharmaceuticals.

6. Loss of social capital.

The capacity of a society to create responsibility, trust and solidarity is impaired.

Consequently, the above authors argued that money is nowhere value neutral. The mechanisms that drive these effects are inherent in the design of contemporary financial system. They further contended that the consequences of such flawed monetary system (i.e. macroeconomic crises) will not be resolved through improved economic policies, technological progress, or by improving a population's educational level. However, the authors did not deliberate any prospective solution to the causes of financial woes that has consistently engulfed the global economy.

\section{Money and Economics from the Syaria Worldview}

Before the syaria standpoint of money proper is presented, it will be useful to first recognise the underlying philosophy of syaria with respect to economic conduct in general.

The fundamental distinction between syaria-induced and conventional worldviews is with respect to the source of legislations and governance relating to economic matters. The syaria (main source being the Muslims' holy book the Quran, followed by the Sunnah as documented in the book of Hadits) outlines a set of rules and principles specifying the norms of conduct in practically all aspects of life including economic matters. While there are specific detailed rulings on the dos and donts in some aspects, in most areas the rulings and guidelines are principles oriented.

Having said the above, the syaria worldview of economics (both positive and normative economics) is one where mankind shall conduct their economic affairs following a given set of rules and values, i.e. derived from and benchmarked by the syaria rulings. Some specifics in economic conduct outlined by the syaria include the forbidding of usury, gambling, gharar, and production/consumption of intoxicating goods. In great contrast, the conventional worldview contends that human beings shall have the liberty to follow own 
values and economic behaviour that are deemed desirable, in which case economic theories and analytical (problem solving) tools are then constructed from observed economic behaviour. Thus, the benchmark of conventional economic models and theoretical validity is whether or not they can explain and correctly predict a particular real world economic phenomenon.

Moving into the dimension of resource and environmental economics, in the syaria, allocation and use of economic resources is seen from the global community and holistic wellbeing (maslahah) perspective. This is in sharp contrast to the conventional practice where economic and specific interests of inhabitants within an enclosed geopolitical boundary (countries) seem to matter most to the domestic policymakers. Such non-cooperative behaviour of nations are however increasingly under challenge and scrutiny by civic-minded international interest groups and consumer groupings, given the advent of sustainable development worldview, globalisation, and global environmental issues that can only be handled through a global platform (e.g. the UN Convention on Climatic Change and Kyoto Protocol on carbon emission reductions).

It is admited that for now no truly syaria society or Islamic economics exists as yet in reality due to many obvious and understandable reasons such as sheer ignorance and the lack of good politics, governance, and economic integration. Nevertheless, given the failures of conventional economic systems and now that the "cultural superiority" of the West has taken a beating, the world has shown an increasing interest in looking for "brand new" solutions to the recurring economic woes. This is where it will be worthy to explore the syaria dimensions of money.

Drawing upon the Islamic tradition and early history, the following attributes of money can be derived or inferred from the teachings of the syaria:

\section{Has Intrinsic or Organic Value}

This criterion markedly differentiates the syaria standpoint of money from the FIAT counterpart. Money to the former is composed of assets which are readily or universally regarded as valuable by mankind. Man has the natural instinct to consider them as worthy for ownership and exchange in the first instance they are faced with such assets. Such assets are normally scarce, durable, divisible, homogenous, and luxurious. Gold and silver easily fall into the domain of such assets, and indeed they have been used as money throughout the ages. 


\section{Means of Exchange without Factor Rents or Interest Income}

Providing a means of exchange is a fundamental function of money in the syaria, as in the FIAT money system too. However, unlike the conventional system, money in the syaria faces a fundamental constraint that it shall not at all earn interest income (or the popular term "MBM" - money begets money). Money is suppose to merely facilitate the transfer of ownerships of goods and in the process shall not earn any factor returns. Such a condition is consistent with the established welfare economics notion that consumers' willingness to pay to obtain a good (normally reflected by the observed market price in a competitive economy without externalities) represents the value of the benefits provided by the good. Under the "MBM" situation, the consumer who made a purchase on credit or taking a commercial loan is very likely to pay an amount higher than his/her true willingness to pay for or the market price of the good by the amount of interest charges (excess payment) served by the capital owner. Hence, the said consumer potentially end up with negative net benefits as whatever consumer surplus the consumer may supposedly enjoy is exploited by capital owners as passive rents or put simply, interest payment on the part of the consumer. It is important to stress here that usury is a big sin in the syaria.

The above argument, however, does not attempt to highlight the demerits of usury in its entirety. It merely seeks to espouse the syaria perspective of money in providing an impartial means of exchange by ensuring that consumers' payment for a good truly reflects the benefits obtained from the said good. As far as factor returns is concerned, money has to be invested strictly in the productive or active sense, say via profit and risk sharing or a mix of profit and risk sharing in any permissible economic indulgence.

\section{Non-Tradable}

Money in syaria is strictly a non-tradable commodity and therefore do not carry "price tags" such as in the form of exchange or interest rates. Such character of money ensures that money will be a true unit measure of value. Of course the quantum of value will depend on one's willingness to pay to obtain a particular goods or services. For instance, while the level of prices of goods or services may be determined by the usual supply and demand forces that vary across regions, it shall not be influenced by variations in the value of money (or currency) itself. This will also mean if one works and earns an income in a particular region, the value of his/her real income 
everywhere else will only be influenced by the prevailing general price level in that locality.

Therefore, money in syaria is akin to a single regional or global currency, hence ideally, a common monetary denomination is advocated for the entire world (recall the syaria considers resource allocation from the perspective of a globally integrated economy, not disjointed by man created political boundaries). On the other hand, under contemporary economics, countries tend to issue own currencies and its value contingent on monetary policy and a host of relevant economic factors.

Given the aforementioned features of money from the syaria viewpoint or at least during the time of the Darul al Medina (first Islamic state), the role of money in the economy shall necessarily be impartial, i.e. yielding intrinsic value, non-tradable, and does not earn factor rents. Such character of money creates an unfettered market where government role in money creation and control will be drastically reduced. Perhaps its only major role in monetary policy will be to ensure that the market runs smoothly. As Friedman puts it, "if money consisted wholly of a physical commodity... in principle there would be no need for control by the government at all". Let it be clear, however, Friedman, like his intellectual foe Keynes, remained supportive of the role of money creation and monetary policy as essential instruments of economic growth.

\section{Financial Crises and Money}

Having presented the preceding arguments, perhaps the recurring global or regional financial crises may not at all be a direct result of bad macro-economic management, but they are fundamentally a manifestation of an inherent systemic weakness associated with the current monetary system. Such systemic weaknesses in essence emanates from the non-impartial character of contemporary money, viz:

- $\quad$ money as a tradable commodity and carries "price tags",

- money that earns passive interest income,

- $\quad$ money (currency) that is subject to speculative attacks, and

- having FIAT-based (non-assets backed) investment instruments, including debt securitisation.

One may then argue, if FIAT money has been the culprit of economic crisis, why has the crisis not persisted with time? To understand 
why the crises had not persisted even though the world was still utilising FIAT money, one would need to reflect on the chain of economic processes in its entirety; from resource allocation to goods production, distribution, consumption, and the externalities that resulted from each of these processes. Owing to the character of financial crises, its effects are logically well apparent, immediate, and market oriented (refer to Figure 1). Nonetheless, it may only be transitory (or a temporary relief) as deliberate policy adjustments are being introduced into the economy. Other manifestations of FIAT money and its accompanying system unfortunately may not be as clear and instantaneous to warrant a quick policy remedy. Taking into consideration the inevitable links between the economyenvironment and extending the thoughts of Brunnhuber et al. (2005), its ramifications would rather be more fundamental and process oriented viz;

unsustainable economic production,

overexploitation of environmental and natural resources, unsustainable consumption, and

socio-economic inequity.

Such subtle repercussions may then lead to persistent degradation of our future generation wellbeing when the capacity of our natural resource base to generate future productive economic processes is being eroded.

The next logical question is; What is the implication of the presumably syaria perspectives of money (if ever prescribed) on economic sustainability and wellbeing? Briefly, these shall be observed through the following manifestations:

ㅁ

Allow only efficient resource use and allocations (real sector transactions, free of influence from inflationary credit or commercial bank money creation) in the entire supply chain of goods and services (resource use-production-final consumption).

No zero sum game in investment and commercial ventures this is to ensure both efficient resource allocation and equitable distribution of benefits and risks, viz mudarabah (profit sharing) and musharakah (risk sharing) or a mix of both instruments. The notion of equitable distribution here relates to the idea that no one party (capital owners or entrepreneurs) can be made better or worse off unilaterally. Furthermore, capital owners shall also be obliged to be active partners and possess business and

IJMS 17 (Special Issue), 35-50 (2010) 
management skills. These are important prerequisites for the enhancement of social capital in a society.

- $\quad$ Safeguard the sanctity of money as a neutral means of exchange and a unit measure of value only, i.e. impartiality of money is attained.

I shall reiterate that the recurring financial crises are not due to the breakdown of the conventional monetarist approach which advocates unfettered market, but fundamentally due to money itself. A return to Keynesians (government intervention) without addressing the fundamental features of money will only bring temporary relief. A mere return to gold or any asset-backed money would not be helpful either. That will only be necessary but not sufficient as long as the right system is not being emplaced.

Macro-economics management should not be an "overly fearful beast" if sustainability is the underlying philosophy. A mix of nontradable commodity-based money and a prohibition of passive income from money (i.e. interest taking), and reliance on profit and risk sharing would lead to production and consumption efficiency and sustainability. Equitable distribution of wealth amongst population groups will ensue. Government spending behaviour would be discreet and efficient in the sense that it would not run on chronic deficits. There will be no easy way and quick fix for "bad" or unsustainable economic growth. These are seemingly ideal development pursuits but surely not undoable. All that are needed are conviction to the new thoughts, commitment to reforms across nations, building a new international finance apparatus while gradually dismantling the entrenched FIAT money and its accompanying institutions. However, should this call to a return to asset or commodity-based money (albeit a basket of commodities) seems very far fetch, given the current global geo-political constraints and the likely resulting deep shocks in the short-run, a practical compromise in the near run would be to identify mechanisms that focus on inhibiting the non-neutrality of FIAT money. This shall include a review of bank reserves and commercial bank money creation to optimise the velocity of money, exchange rate regimes that ensure currency stability, as well as business/investment dealings not backed by the real economy.

\section{Advocates of Gold Standards}

While the majority of economists are at best lukewarm to the idea of commodity-based money or gold standards, there are quite a number of renowned economists and individuals who have been 
strong advocates of the gold standard. Especially notable are the economists affiliated with the so-called Austrian School of thought or the Vienna School economists. They promote free markets, where government intervention, especially in monetary policies is reduced or minimal. Such economists include the Nobel Laureate Friedrich Hayek. The former US Federal Reserve Chairman Alan Greenspan and notable macro-economists Robert Barro have also expressed support for the return of the gold standards. Way back in 1966, interestingly Alan Greenspan (1966) wrote a paper titled "Gold and Economic Freedom" which argued that supporters of FIAT money are advocates of monetary policies that include the financing of government deficits. There are also a number of US Congressmen who argued for the restoration of gold as money. However, it is hastened to note here that such calls for the return of gold standards, or assetback money in general, have not been accompanied by an equally pressing premonition for an appropriate financial and regulatory system to ensure and safeguard the impartiality of money, i.e. viz, non-tradable, non-interest bearing, and non-debt financing attributes, amongst others.

\section{Conclusions and Implications}

The paper has highlighted the syaria standpoint of the impartial character of money as the fundamental factor that differentiates money from FIAT money as conventionally adopted. It was argued that while it is important for asset-based money to make a comeback in the interest of sustainable development and holistic wellbeing of humankind, it is neccasary to complement it with an appropriate financial and regulatory system to safeguard its impartiality, i.e. viz, non-tradable, non-interest bearing, and non-debt financing to avoid the recurring pitfalls which are imminent in the onventional financial system. Neutral money, even under a modified FIAT money system is imperative in any new financial architecture to ensure development and wellbeing sustainability.

\section{Endnotes}

1. I define Sustainable Wellbeing as simply the conventionally understood notion of Sustainable Development plus the elements of freedom, happiness and contentment. Sustainable Development is a necessary but not sufficient condition for Sustainable Wellbeing.

IJMS 17 (Special Issue), 35-50 (2010) 
2. One fine day in April 1997, just two months before the onslaught of the Thai Baht, the writer was at the grand hall of the prestigious Magister Management Programme, Gajah Mada University, Jogjakarta, Indonesia, proudly delivering a public lecture titled "Towards Economic Dynamism: The Malaysian Way". Barely two months later, as the lecture material was about to be published by the university's Jurnal Kelola, the Asian financial crisis struck. What a mockery of our intellect! It was undeniably this deep irony that has prompted the writer to indulge on research affecting money, financial system and sustainability.

\section{References}

Brunnhuber, S., Fink, A., \& Kuhle, J.-P. (2005). The financial system matters: Future Perspectives and scenarios for a sustainable future. Futures, 37, 317-332.

Greenspan, A. (1966). Gold and economic freedom. Retrived from http// www.321gold.com/fed/ Greenspan/1966.html

Jamal Othman. (2003). Work program to strengthen capacity for social impact assessment of economic crisis and improved poverty measurement in ASEAN: An output of ASEAN-UNDP ASP-6 Project. Ministry of Rural Development Malaysia ans ASEAN Secretariat. 
Appendix 1

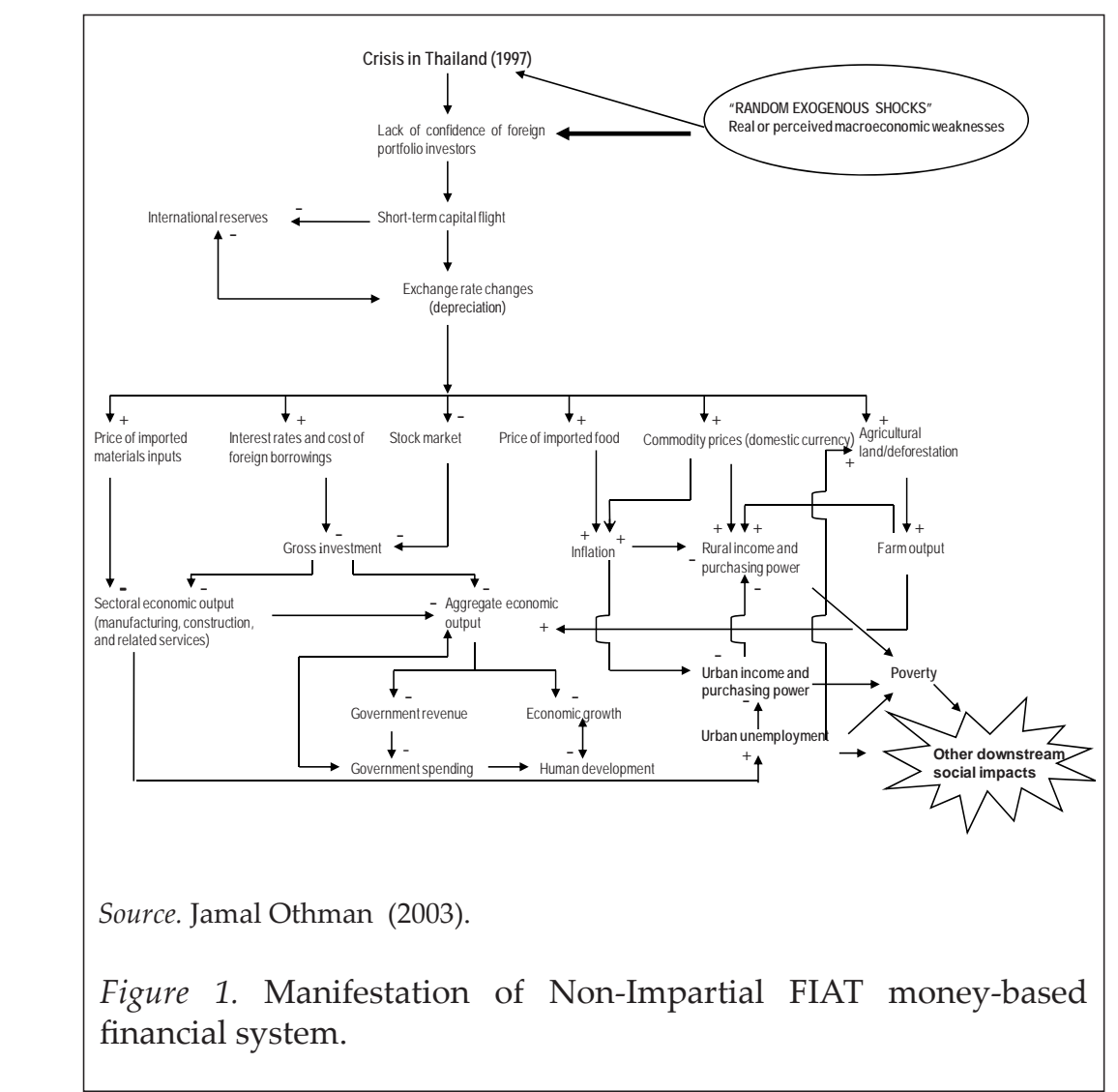

50 IJMS 17 (Special Issue), 35-50 (2010) 